\title{
Teacher Effectiveness Examined as a System: Interpretive Structural Modeling and Facilitation Sessions with U.S. and Japanese Students
}

\author{
Alexia Georgakopoulos \\ Department of Conflict Analysis and Resolution \\ Graduate School of Humanities and Social Sciences \\ Nova Southeastern University \\ 3301 College Avenue, Ft Lauderdale FL 33314. \\ Tel: (954)262-3054. Fax: (954) 262-3968Ｅ-mail: Georgako@nova.edu
}

\begin{abstract}
This study challenges narrow definitions of teacher effectiveness and uses a systems approach to investigate teacher effectiveness as a multi-dimensional, holistic phenomenon. The methods of Nominal Group Technique and Interpretive Structural Modeling were used to assist U.S. and Japanese students separately construct influence structures during facilitation sessions. The influence structures represent maps for understanding teacher effectiveness as a system. The influence maps indicate that there are a number of teacher behaviors and characteristics that promote, support and influence one another within the overall system; however, the plurality of teacher elements, which are structured with priority, concerns teacher knowledge characteristics and verbal teacher immediacy behaviors for both cultural groups. The findings of the study were explored from thematic perspectives in intercultural communication such as power distance, identity and contact orientation. Given the qualitative nature of the study, participants' own theories-in-use were important in the study. Also, Confucianism principles were significant in the Japanese assessment of teacher effectiveness. The study has implications for professors across fields since the majority of professors are educators who have not been formally trained in the education field. The study points to the importance of ongoing faculty development in teacher effectiveness.
\end{abstract}

Keywords: Teacher effectiveness, Systems approach, Nominal Group Technique, Interpretive Structural Modeling

\section{Introduction}

The more vantage points we use to understand teacher effectiveness, the more complete our understanding will be about its complex nature. Communication education scholars are faced with the incredible challenge of not only understanding communication, but also understanding culture within the teaching and learning context. A number of scholars across disciplines have addressed the issue of teacher effectiveness (Aubrecht, 1981; Cashin, 1994; Furhrmann \& Grasha, 1994). After reviewing more than 1,300 research pieces on student ratings of teaching, Cashin (1994) argued that "there is no agreed upon definition of 'effective teaching' nor any single, all-embracing criterion" (p. 533) and further suggested that "no single source of data...provides sufficient information to make a valid judgment about teaching effectiveness" (p. 531). Considering the complexity of teacher effectiveness, communication education scholars need alternative models to better understand and assess teacher effectiveness since no single model should be considered sufficient or superior. This study was designed to examine teacher effectiveness globally as a set of relationships among a number of teacher behaviors and characteristics. This methodology is different from the majority of past research in teacher effectiveness and immediacy, which have examined one or a few constructs in isolation (Allen, Witt \& Wheeless, 2006; Johnson \& Miller, 2002; Teven \& Hanson, 2004). The dynamic relationships involved with a host of teacher communication behaviors and teacher characteristics in relation to teacher effectiveness are to date largely unknown; therefore, a systems approach has great merit in communication education research since it involves discovering how the different teacher communication behaviors and characteristics interact and work together. Nuanced relationships can be captured and the interplay of teacher behaviors and teacher characteristics can be assessed. Social science research has successfully used the systems approach to facilitate our understanding of organizations, families, society, conflict (Schellenberg, 1996) and diversity (Broome, DeTurk, Kristjansdottir, Kanata, \& Ganesan, 2002).

\subsection{The Concept of an effective Instructor}

What is an effective instructor? Researchers and scholars involved in instruction have sought answers to this important question and years of research have been devoted to answering this question (Powell \& Arthur, 1985; Nussbaum, 1992). Given current globalization trends, understanding teacher effectiveness across and within cultures should be at the forefront of concern for communication education scholars. As Gay (2006) stated "a semiotic relationship exists among 
communication, culture, teaching, and learning, and it has profound implications for implementing culturally responsive teaching" (p. 326). Culturally responsive teaching largely relies on an emic or insider understanding of teacher effectiveness yet studies from this perspective are limited.

What is clear from past research is that Mehrabian's (1971) concept of immediacy, Andersen's (1979) further delineation of nonverbal immediacy, and Gorham's (1988) extension of immediacy to verbal immediacy are important since substantial research indicates that nonverbal and verbal immediacy positively relate to teacher effectiveness as well as student learning outcomes for domestic and international students (Collier \& Powell, 1986; Collier, Ribeau \& Hecht, 1986; Johnson \& Miller, 2002; Powell \& Harville, 1990; Sanders \& Wiseman, 1990).

First, the purpose of this study is to problematize U.S. definitions of teacher effectiveness and teacher immediacy often used in communication education research and to apply alternative methods to explore these phenomena. Second, the study will focus on criticisms of cross-cultural applicability of immediacy (Zhang \& Oetzel, 2006), lack of emic notions of teacher effectiveness, and uncertainty about how teacher effectiveness functions as a system.

\section{Literature Review}

\subsection{Applicability of Teacher Effectiveness and Culture}

Teacher effectiveness is dynamic and complex. Examination of the U.S. education literature supports this sentiment, as there is no clear agreement on the definition of teacher effectiveness. Cashin (1994) concluded that there is a plurality of ideas surrounding what constitutes teacher effectiveness. Despite these arguments, the conceptualization of teacher effectiveness most popularly used by communication education scholars is Andersen's (1979) definition: "one who produces positive outcomes in all three domains of learning: student affect, behavioral commitment to the course content, and student cognitive learning" (p. 54). Andersen's measure of teacher effectiveness is culturally bound and culturally grounded; therefore, her measure may likely be culturally incommensurable when applied outside the U.S. Narrow definitions limit our understanding of a phenomenon. Approaching three decades, Andersen's (1979) conceptualization of teacher effectiveness requires critical examination from contemporary communication education scholars. If we continue to use the same lens we limit what we can observe. No teacher behavior functions separately and in a vacuum, thereby supporting the application of a systems approach in the investigation of teacher effectiveness. The next section critically examines teacher immediacy as it relates to teacher effectiveness within cultures.

\subsection{Culture and Teacher Immediacy}

"Teacher immediacy has received unsurpassed scholarly attention in the field of instructional communication over the past three decades" (Zhang, Oetzel, Gao, Wilcox and Takai, 2007, p. 228). The concept has also been shown to garner positive student outcomes across cultures (Johnson \& Miller, 2002; Roach \& Byrne, 2001; Zhang \& Oetzel, 2006). Despite the popularity of teacher immediacy, several problems surround its assessment across cultures. Most problematic is that the operational definition of teacher immediacy is used as a 'main mean' for making cross-cultural comparisons (Johnson, \& Miller, 2002; Neuliep, 1997; Roach \& Byrne, 2001; Zhang \& Oetzel, 2006). The majority of research executed across cultures has measured teacher immediacy according to Andersen's (1979) conceptualization of teacher effectiveness or one type of her measure of learning without a critical examination of the effects of culture.

Other researchers have reported problems with the validity of verbal immediacy (Mottet \& Richmond, 1998; Richmond, McCroskey \& Johnson, 2003; Robinson \& Richmond, 1995) and nonverbal immediacy related to cultures outside of the U.S. (Zhang \& Oetzel, 2006). Mottet and Richmond (1998) reported that verbal immediacy should include a repertoire of text-based linguistic codes. Zhang and Oetzel (2006) argued that the focus of verbal immediacy should be on content messages rather than on the modality of messages. They argued for an emic perspective given the controversy surrounding verbal immediacy across cultures. In a unique emic study, Zhang and Oetzel (2006) found that Chinese notions of teacher immediacy are qualitatively different from the United States notions, therefore it stands to reason that across disparate cultures teacher immediacy should take different forms and functions as well. It is important for communication education scholars to examine the cultural meanings associated with teacher immediacy as well as the unique teacher outcomes that ensue from teacher immediacy expressions.

The role of teacher immediacy in relation to other teacher behaviors and characteristics is important considering that instructor use of both verbal and nonverbal immediacy behaviors has been associated with student perceptions of instructor use of other communication behaviors (Myers, Zhong, \& Guan, 1998). For example, past research has shown that immediacy is associated with perceptions of instructor clarity (Powell \& Harville, 1990), humor orientation (Wanzer \& Frymier, 1999), instructor socio-communicative style (Thomas, Richmond, \& McCroskey, 1994), instructor use of behavior alteration techniques (Kearney, Plax, Smith, \& Sorensen, 1988), teacher competence and trustworthiness (Teven \& Hanson, 2004), motivational factors for student learning (Allen, Witt, \& Wheeless, 2006), teacher credibility (Johnson \& Miller, 2002), and other positive outcomes. Allen, Witt, and Wheeless (2006) argued that an immediacy learning process exists; however, the interrelationships and the particular content involved in this process need to be examined. They argued that their meta-analysis and previous meta-analysis studies do not capture the 
function, influence, evaluation, and direct assessment of immediacy in relation to student evaluations of their teachers. The dynamic relationships involved in a host of teacher communication and teacher characteristics in relation to teacher effectiveness are to date largely unknown. Therefore, this study represents a step in the direction to advance this type of research.

Although the immediacy-exchange theories including Burgoon's (1978) expectancy violation theory, Capella \& Greene's (1982) discrepancy-arousal theory, and Andersen's (1998) cognitive valence theory yield different predictions for changes in immediacy behavior, they all stress that interpretations, expectations, and evaluations of immediacy are significantly guided by culture. It is clear that culture plays a key role in assessment of immediacy. Consequently, this study explores how teacher immediacy and a variety of teacher characteristics influence each other according to a group of United States and Japanese students who represent two distinct cultural groups.

\subsection{Culture and Theoretical Framework}

Culture is pervasive and it permeates social interactions in instructional contexts. Thus, any investigation of the instructional setting must be done with an acute awareness of the cultural landscape that exists since it is clear that cultural factors mold teachers' status, demeanor, and relations with students. The cultural dimensions that are important to the current study are power distance, identity, and degree of contact communication. These dimensions have been popularly used to understand communication across cultures (Andersen \& Wang, 2006). The United States and Japan differ in terms of their general orientations toward power distance, nonverbal communication and immediacy (Andersen, 2008). Most notably, Confucianism significantly influences Japanese orientations toward collectivism, high power distance, and teacher communication, whereas individualism influences United States orientations toward low power distance and teacher communication.

The Individualism/Collectivism construct describes the relationship between the individual and the group surrounding him or her in a given society (Hofstede, 1980). Individualism emphasizes the particular self and uniqueness. Collectivism, on the other hand, is the opposite; members of a collectivistic society underscore in-group interests, conformity, and cohesion. According to Hofstede (1980), the United States is considered the most individualistic country in the world while most Asian cultures (e.g., Japan, Singapore) are considered collectivistic. Triandis (1995) examined this construct further and suggested individuals in cultures express both individualist and collectivist themes. He presented individual level values of the self, based on independence or interdependence as well as similarity or difference. He referred to the all the combinations of self as horizontal collectivist, vertical collectivist, horizontal individualist, and vertical individualist. This research indicates that it is wise for researchers to explore the inclusion of both individualism and collectivism within cultures.

Another important dimension of culture to this current study pertains to power distance. Mulder (1977) argued that across every society those holding high status strive for the maintenance or enlargement of distance between themselves and those in lower status. In cultures influenced by Confucianism, high power distance is accentuated by communication behaviors that support hierarchical relationships. Authoritarianism is closely related with the power distance index (Hofstede, 1980). Individuals from low power distance societies strive for the reduction of distance and accentuate communication behaviors that support egalitarianism and closeness. Immediacy behaviors should be in conflict with high power distance cultures and in congruence with low power distance cultures since Mehrabian's concept of immediacy reduces physical and psychological distance through behaviors that convey interpersonal warmth, intimacy and availability for communication. Also, the cultural distinction between contact and noncontact cultures is noteworthy when describing communication within United States and Japanese cultures (Hall, 1966). People in contact cultures typically are nonverbally expressive, which leads to more overall sensory stimulation. By contrast, people in noncontact cultures are nonverbally distant and more emotionally reserved. Andersen (2008) presented evidence that Japan is a noncontact-oriented culture while the United States is moderate to moderately high in terms of contact orientation.

Given the emic nature of the current study, a Japanese perspective was necessary. McDaniel's (2006) Japanese cultural thematic analysis of communication provided a useful framework for understanding a Japanese perspective. She linked Japanese nonverbal communication with the following cultural themes: hierarchy, harmony (wa), empathy, interdependence, formality (ritual expression, protocol compliance, and tradition), humility, sacrifice (gaman), perseverance, and Confucian-rooted collectivism. She concluded that superior nonverbal understanding results from a relatively homogeneous, collectivistic-Japanese culture. This closeness supports nonverbal familiarity, intuition and tacit understanding while it takes precedence over verbal discourse. While McDaniel (2006) limited her investigation to nonverbal communication, cultural themes can be applied to verbal communication as well.

Finally, it stands to reason that unique cultural interpretations will surround the behaviors that support teacher effectiveness since the United States and Japan are distinct. Given the qualitative nature of the present study, it is important to discover participant's own theories about the meaning of teacher communication that supports teacher effectiveness. According to Nishida (1996), communication theories from the United States have been criticized for 
their application in Japan and "this has resulted in arguments regarding general views about nature, human relations, and communication, and the unique characteristics of Japanese communication patterns" (p. 102). Schwarz (2002) used the term theory-in-use to exemplify checking in with participants during facilitation sessions in order to tap into member meanings. The purpose of this study is to better understand teacher effectiveness, from the people who talked about teacher effectiveness so the study is open to emergent theories-in-use. Given the lack of research concerning emic notions of teacher behaviors and teacher characteristics, the following research questions were formulated:

RQ1: What types of immediacy behaviors and teacher characteristics promote student perceptions of teacher effectiveness within the U.S. culture?

RQ2: What types of immediacy and teacher characteristics promote student perceptions of teacher effectiveness within the Japanese culture?

Particularly interesting in immediacy research performed within cultures is the degree of influence that immediacy has on other teacher characteristics. Currently, no study has investigated immediacy in terms of generating "influence maps" that position immediacy in relation to other effective teacher characteristics within particular cultures. Given the lack of a systems approach in the investigation of teacher effectiveness, the following research questions were formulated:

RQ3: How do different immediacy behaviors and teacher characteristics significantly influence, support, and relate to student perceptions of teacher effectiveness for a group of U.S. students?

RQ4: How do different immediacy behaviors and teacher characteristics influence, support, and relate to student perceptions of teacher effectiveness a group of Japanese students?

Research questions three and four are proposed to explore the nuanced relationships involved in student assessments of teacher effectiveness from an emic focus. The specific purpose underlying these research questions is to obtain a better understanding of the influential agents that significantly support student perceptions of teacher effectiveness for each cultural group.

\section{Methods}

The methods of Nominal Group Technique (NGT) and Interpretive Structural Modeling (ISM) were used to assist separately United States and Japanese students in constructing influence structures during facilitation sessions. Nominal Group Technique (Broome \& Cromer, 1991; Delbecq, Van de Ven, \& Gustafson, 1975) provided information that was necessary in the early stages of the study while Interpretative Structural Modeling was applied to the majority of the study in the facilitation workshops (Broome \& Cromer, 1991; Warfield, 1976).

\subsection{Process}

NGT is a method that allows ideas to be generated in relation to a situation that is surrounded with uncertainty. It has been associated with five distinct and important steps (Broome \& Cromer, 1991; Delbecq, Van de Ven, \& Gustafson, 1975). First, the technique requires that a query of interest be presented to a group in the form of a question that is designed to stimulate ideas. Second, NGT requires a group of people to generate ideas individually. Thus, ideas are generated silently without external distraction, evaluation, or judgment. Third, the set of ideas generated by individuals in the group are visually displayed for all group members to view. Fourth, participants in the group become familiar with all ideas through a serial discussion and clarification of items. The firth and final step in NGT is a voting procedure that requires all members in the group to select the most salient items.

Interpretive Structural Modeling (ISM) is associated with the more global problem solving design of Interactive Management (IM). Interactive Management was developed to deal with complex issues that are not easily approached by traditional methods of problem solving (Broome, 1997; Warfield, 1982; Warfield, 1995; Warfield \& Cardenas, 1995). Additionally, IM adheres to three important characteristics proposed by Broome and Christakis (1988) in order to create a culturally-sensitive methodology. The first characteristic is a holistic approach where there is "recognition of the systems nature of combinations of ideas and entities" (p. 221). Second, a process orientation must be adopted where "those who 'own' the issues become engaged and responsible for dealing with them, thus preventing the imposition of external perceptions on the definition... of the...situation" (p. 221). Because IM promotes collaboration of group members who share a commitment in addressing complex issues within a framework that utilizes systematic and logical reasoning, the design provides a powerful methodology to unveil the complexity involved in understanding teacher effectiveness within culture.

The use of the ISM methodology is comparable to focus group sessions in several respects. First, like focus groups, ISM draws from gathering participants who have experience and knowledge about an issue. As Blumer (1969) spoke of the power of utilizing a select group: he suggested "seeking participants... who are acute observers and who are well informed....A small number of such individuals brought together as a discussion and resource group, is more valuable many times over than any representative sample" (p. 41). 
Unlike the focus group, however, ISM is a computer-assisted methodology that has the advanced feature of software that uses "mathematical algorithms that minimize the number of queries necessary for exploring relationships among a set of ideas" (Broome, 1998, p. 4; see also Warfield, 1976). Therefore, the nature of the current study is quantitative as well as qualitative. The ISM software program facilitates what otherwise might be an impossibly complex task of organizing items into a comprehensible set of relationships and displayed as a structure (Broome, 1998). ISM can be used to develop several types of structures (Broome, 1998), but for the purpose of the current study the supportive influence type structure was selected.

\subsection{Participants}

The United States and Japan were selected for this study because cross-cultural research most notably compares Eastern and Western cultures because these cultures are culturally distinct (Zhang, Oetzel, Gao, Wilcox \& Takai, 2007). Japan typically is identified as a Confucian-based collectivistic, high power distance, low immediate, noncontact culture and in contrast the United States typically is identified as an individualistic, low power distance, contact, and high immediate culture (Zhang, Oetzel, Gao, Wilcox \& Takai, 2007). Additionally, differences between the United States and Japanese communication patterns have been widely documented in past research in terms of communication theories, personal relationships (Nishida, 1996), facework strategies (Cupach \& Imahori, 1993), self-disclosure, self-knowledge, boundaries of public/private self (Asai \& Barnlund, 1998), and immediacy behaviors (Neuliep, 1997).

A group of 14 Japanese students formed one group and a group of 13 U.S. students formed a second group. Each group separately participated in an idea generation and idea structuring workshop. The Japanese group included six males and eight females. The U.S. group included six males and seven female students. The average age for the Japanese group was 20. The average age for the U.S. group was 22. Japanese students had advanced English proficiency and lived in the U.S. for less than a year. Participants were selected according to Morse's (1994) criteria of a good informant as "one who has the knowledge and experience the researcher requires, has the ability to reflect, is articulate, has the time to be interviewed, and is willing to participate in the study" (p. 228). The study viewed students as a site for understanding effective teacher behaviors and teacher effectiveness. This view of students was based on recommendations of Tanno and Jandt (1994), who called for a need to redefine the "other" in research as participants, experts, and co-producers of knowledge, and Broome (1991), who emphasized the need to form an understanding by "co-creating with the other a shared reality" (p. 247).

The researchers solicited Japanese and U.S. students through various instructors on campus as well as through the technique of snowballing. As an incentive, both set of students were informed about their opportunity to learn facilitation techniques and meet new people.

\subsection{Conceptual Definition of Teacher Effectiveness}

Notions of teacher effectiveness in the present study draw on students' local knowledge concerning this phenomenon in the context of instruction. Students were asked to reflect on their "best teacher" in college who they perceived to be "effective." Thus, the phenomenon of teacher effectiveness was not discovered from an a priori framework, but rather from particular communities (students) speaking about particular situations (effective teaching). Teacher effectiveness in this examination is defined in terms of teacher processes whereby a number of teacher behaviors/communication and characteristics are thought to significantly interact, influence, promote, and support each other within an overall system.

\subsection{Procedures}

During this project, Nominal Group Technique involved the following steps: (1) presentation of a triggering question that was provided two weeks prior to the workshop in a questionnaire, (2) silent generation of ideas in writing by each student in response to an open-ended questionnaire, (3) display of ideas collected from the group on surrounding walls, (4) serial discussion of the generated ideas that allowed clarification and editing of ideas, and (5) selection by the participants of the more important items through a voting process. The workshop began with the context statement that the facilitator read to participants as follows:

In today's U.S. classrooms, it is increasingly necessary to understand how teacher verbal and nonverbal behaviors and characteristics of a teacher contribute to teacher effectiveness. Many academic institutions have recognized the need for training that helps teachers promote their effectiveness, but many of these programs do not allow sufficient time for students to voice and examine many of the critical issues involved, and participants are often not able to fully share their experiences and views. This workshop is designed to allow students an opportunity to examine a wide range of factors that are important for the establishment of teacher effectiveness, and it will help students explore how these factors influence one another.

After the facilitator provided participants with a clear overview and objectives for the

day's activities, the facilitator recapitulated the "triggering question" as following: 
Imagining a best teacher who you also perceive to be your most effective teacher you have ever had in college (in your home culture), answer the following questions:

(1) What are all the teacher characteristics that you associate with this teacher?

(2) What are the verbal and nonverbal behaviors that you associate with this teacher?

Since the focus of the study was to determine more precisely the role of verbal and nonverbal immediacy in effective teaching, all behaviors associated the construct of verbal immediacy (Gorham, 1988) and nonverbal immediacy (Richmond, Gorham and McCroskey, 1987) as U.S. derived were displayed on butcher-block paper and placed on the walls during the workshop. Students in both groups were able to select their preferences among the immediacy behaviors during the workshop.

After the idea generation phase, students were asked to place items in appropriate categories based on emergent themes and extant research. When items did not fit an extant category, the process was open to a new emergent category. Notably, Nassbaum's (1992) comprehensive review of literature concerning effective teachers, which included one thousand studies gathered from 1983 to 1990, was used as a basis for developing categories in the current study which included the following extant categories: immediacy behaviors (verbal and nonverbal), clarity characteristics, relational characteristics, organization and class control characteristics, affective characteristics, skill characteristics, personal characteristics, knowledge characteristics, goal and outcome characteristics (Nussbaum, 1992).

Next, the workshop was devoted to steps involved in Interpretive Structural Modeling (ISM). In this phase, students were asked to make pair-wise comparisons between highly desirable teacher behaviors and characteristics using the contextual relationship: "In the context of imaging your best and most effective college instructor in your country, does: ...A significantly promote B?" Through discussion, the students were asked to provide a rationale for a "yes" vote and "no" vote. Both groups of students spent approximately seven hours making judgments about the relationship between pairs of ideas, with ISM computer assistance.

The last hour was devoted to understanding, displaying and discussing the influence map, and amending ideas as desired by the participants. The group agreed on a majority vote rule when ambiguity surrounded an items' placement in the map. Thus, items were not viewed as static but rather in flux in relation to members' meanings.

\section{Results}

Two workshops were held. "Workshop One" included U.S. students and "Workshop Two" included Japanese students. The first research question inquires about the types of immediacy behaviors and teacher characteristics that promote student perceptions of teacher effectiveness within the U.S. culture. The U.S. group generated 120 items in response to this question. The second research question is identical but inquires for a Japanese perspective. Japanese students generated 124 items. Priority selections for the U.S. group are featured in Appendix A and priority selections for the Japanese Group are featured in Appendix B. These items reflect each group's perceptions of the major contributors in the promotion of teacher effectiveness.

Research questions three and four inquire about the saliency, influence, interrelationship, and support among elements involved in teacher effectiveness for each cultural group. U.S. students structured 39 of the 120 items in their influence map. Japanese students structured 33 of the 124 items they generated. The influence maps are illustrated in Appendix C for the U.S. students, and Appendix D for the Japanese students. The maps represent the interrelationship among elements using the relational question: "significantly promotes."

The influence maps featured in Appendices $C$ and D should be read from bottom to top, with the elements at the base of the structure exerting the majority of influence to the remaining items in the structure. The arrows identify the direction of positive influence and relationship among items. Arrows connect elements that receive the most immediate support. The letters next to each item identify it in terms of category. Boxes around elements indicate a cycle, which suggests that elements are related and have the same degree of influence within the influence map. Elements toward the top of the influence map receive support from all elements preceding them if an arrow connects them. The numbers are included for identification purposes only and do not indicate priority or weight. The influence maps are referred to as the "Supportive Cultivation of Teacher Effectiveness" for each culture and the specific findings for U.S. and Japan are discussed below.

\subsection{Findings from U.S. Group's Supportive Cultivation Map of Teacher Effectiveness}

The U.S. Supportive Cultivation Influence Map featured in Appendix C revealed several important findings. The structural analysis indicated that there are three lines of influence affecting the structure. Distinct paths with high priority selections followed from Knowledge Characteristics (Category E) and Verbal Immediacy Behaviors (Category A). Although Skill (Category J) was not as influential as the above mentioned categories in the map, one element (J-85) - "Keeping the class interesting" came from this category at the base of the structure and defined the third path of influence. 
A total of nine verbal immediacy items appeared in the map with three verbal immediacy items observed in the first stage. The three verbal immediacy items located at stage one extended influence to a total of 29 other supportive elements and involved teacher praise, student feedback and answer solicitation. Thus, 74\% of the remaining items on the map were supported by these three items, which accounted for a significant percentage of the total support in the cultivation of teacher effectiveness. Also, five items from the Knowledge Category appeared in stage one and are reflected in three separate cycles. Qualitative differences emerged in the knowledge category since separate cycles were found. The first cycle associated with teachers who keep abreast of topics they teach, and who are proficient in their subject area and influenced 23 items on the map, meaning that $59 \%$ of the remaining items on the map were supported by this cycle. The second cycle indicated that U.S. students valued teachers who have acquired experience outside of the academic setting and extended influence to a total of 16 other items, meaning that this item influenced $41 \%$ of the remaining items. The third cycle indicated that students valued teachers who have proficiencies in teaching styles and influenced a total of 16 other items, meaning that $41 \%$ of the remaining items were influenced by this cycle. After these categories and specific items are considered, other categories located further up in the influence map should be addressed.

Items located at the top of the structure received a high degree of support in the overall system and most notable associated with Affective Characteristics (Category H). Relational Characteristics (Category I) and Organization/Class Control Characteristics (Category D) were also supported significantly but to a lesser extent.

\subsection{Findings from Japanese Group's Supportive Cultivation Map of Teacher Effectiveness}

The Japanese Supportive Cultivation Influence Map featured in Appendix D revealed several important findings. Two distinct paths of influence were noted that followed from two items involved with Knowledge Characteristics (Category E). Thus, the knowledge category provided the majority of support to the remaining elements in the structure. Specifically, "Having knowledge in many different areas" (E-25), which is located at stage one extended influence to a total of 29 other supportive elements. Thus, this single item supported $88 \%$ of the remaining items on the map. Also, "Having real-world experience outside of the class" (E-111), exerted support to 85\% of the remaining items on the map. Important, but to a lesser extent than knowledge, Skill (Category J) was presented at the base of the structure and included items "Using time well," (J-26) and "Having adequate teaching ability and/or communicative skill," (J-26), which provided support to a significant number of elements in the structure.

In the assessment immediacy behaviors, seven verbal immediacy and two nonverbal immediacy behaviors were structured in the influence map. Thus, verbal immediacy had more significance in the overall system. The verbal immediacy item that received high priority related to teacher feedback. In terms of nonverbal immediacy, eye contact was important. The teacher characteristics that received a high degree of support within the system included the large cycle of 10 items found in stage seven. Thus, the structural analysis of the Japanese Supportive Cultivation Map showed that the categories titled Affective, Clarity, and Goal/Outcome received a high degree of support within the overall system.

\section{Discussion}

Considerable research in the cross-cultural communication field calls for alternative research methods that use alternative paradigms to understand cultural phenomena (Carbaugh, 1990; Hecht, 1993; Martin \& Nakayama, 2000; Zhang, \& Oetzel, 2006). Also, researchers (Shuter, 1998) stress that more work should investigate cultures using rich descriptions akin to earlier research studies (e.g. Hall, 1966). Because of the systematic and integrative nature of group problem solving, NGT and ISM offered powerful methodologies for exploring student's rich descriptions of teacher behaviors and characteristics following a systems approach. The findings reveal what teacher behaviors and characteristics promote, influence, cultivate, and support student perceptions of teacher effectiveness. This study supports the concept that culture shapes preferences for teacher effectiveness in both United States and Japanese students.

\subsection{Discussion of Findings for U.S. Students}

The base of the U.S. influence map points to knowledge characteristics and verbal immediacy as the categories that exerted the highest influence on all other categories. Specifically, in the eyes of students, teachers with applied backgrounds were preferred over teachers who had primarily an academic background. Students expressed that teachers with these backgrounds effectively translated course concepts into to real world applications. Also, U.S. students emphasized preferences for teachers who have been trained both in their subject area as well as in instructional pedagogy. These findings indicate that teachers' mastery and experience within their subject area are not sufficient for their students. Students in the current study explained that their effective teachers understood "effective teaching practices" and applied them in the class. Students expressed a strong desire for teachers to receive ongoing training in effective teaching. Interestingly, the majority of U.S. academic institutions have mandated student evaluations as a 
means of determining teacher performance. This institutionalized practice may work as a reminder for students to value not only what is being taught but also how they are taught.

Interestingly, the knowledge characteristic category directly influenced elements in the teacher verbal immediacy category. U.S. students' preferences for verbal immediacy were not surprising, given that verbal immediacy is a U.S. originated construct. The United States is an individualistic culture whose members prize verbal communication over nonverbal communication because of the heterogeneous nature of the culture (Hostede, 1980). Also, U.S. culture is affiliated with competition, uniqueness and individuality. The immediacy priority selections, such as praising an individual student and giving feedback on an individual's work focus on individual level rather than group level teacher responses. These elements support individualistic identity, low power distance, and contact orientation affiliated with dominant U.S cultural values. U.S. students in the current study stated that their preferences of verbal immediacy over nonverbal immediacy were due to the concrete and direct nature of verbal immediacy. They explained that the meanings associated with nonverbal immediacy messages are more difficult to interpret across teachers especially in light of cultural differences between them and their teachers. Research by Smythe and Hess (2005) supports this finding as they found a discrepancy and insignificant relationship between student reports and coded observations of teacher nonverbal immediacy. Also, students in the current study expressed a desire for a democratic relationship with their teachers and that verbal immediacy expressions supported this relationship. Verbal immediacy actions signal a reduction of physical and psychological distance and communicate warmth, approach, and availability for communication (Andersen \& Wang, 2006). These qualities are consistent with individuals operating at low power distance (Hofstede, 1980). Cultures with low power distance encourage expressions that reveal a reduction of distance.

Another notable example of verbal immediacy in the study was humor. Given that the United States is a society that prizes not only individualism but also entertainment, this finding was not surprising. For U.S. students, the expectation and desire of an interesting class promoted a teacher's use of humor. A teacher's use of humor subsequently supported creativity in teaching and ultimately supported the affective component associated with teacher effectiveness. Wanzer and Frymier (1999) reasoned "students may pay more attention and be more willing to attend class when humor is used regularly in the classroom. Using humor to present information may make the content more memorable, helping students to retain more information" (p. 58). Additionally, Appendix A includes all top priority selections in verbal and nonverbal immediacy.

The path of influence leading from items associated with verbal immediacy and knowledge categories affected numerous teacher characteristics and behaviors; however, the plurality of items they supported concerned a teacher's expression of affect toward students and the subject being taught. These findings are in alignment with Andersen's (1979) work that indicated the existence of an immediacy-affective relationship. While support was found for this relationship in the current study, the findings indicate that the relationship is significantly more complex than Andersen (1979) had initially conceived, since the current study provides evidence that immediacy interplays with a variety of teacher communication and characteristics to ultimately support the immediacy-affective relationship.

\subsection{Discussion of Findings for Japanese Students}

Turning to the influence map generated by Japanese students, it was necessary to couch the findings in reference to the Japanese culture, which has roots in Confucian-based collectivism (McDaniel, 2006). In fact, Confucian principles have existed for hundreds of years in Japan and are embodied in the Japanese educational ideology (Yum, 1997). Due to the historical influence of Confucian philosophy in Japanese education, it is not surprising that Japanese students structured the knowledge category with high priority at the base of the influence map. One of the four principles of Confucianism includes chih (wisdom or a liberal education), which relates to knowledge (Yum, 1997). According to Chen and Chung (1997) "the perfectibility and educability of human beings is central to Confucian thinking" (p. 322). The Confucian emphasis on education functions as a great asset in the economic prosperity and modernization of Japan (Chen and Chung, 1997). In the context of Confucian traditions, wisdom, knowledge, and the role of a teacher are held in high regard since they have a significant impact on the benefit of the collective culture (Myers, Zhong, Guan, 1998). The influence map generated by the Japanese students supports these concepts.

Additionally, Japanese students emphasized several items from the skill category, which were structured with high priority in the overall influence map. Japanese students perceived that their best teacher expressed strong communication skills, teaching skills, and time management skills. Several of the skill characteristics supported Japanese cultural themes described by McDaniels (2006). For example, time is highly valued in Japan so formality to time protocol is expected (Andersen \& Wang, 2006). According to the Japanese students, being skillful is woven into the fabric of Confucian-based teachings.

The influence map corresponding to the Japanese group included only a few nonverbal immediacy elements. This finding is in alignment with the noncontact orientation and high power distance dimension, which are affiliated with Japanese and other Asian cultures (Andersen \& Wang, 2006). Japanese students in the current study provided their explanation that the U.S. concept of nonverbal immediacy is not part of the behavioral nonverbal repertoire used by 
Japanese teachers. This finding is consistent with McDaniel's (2006) comprehensive study of Japanese nonverbal cultural themes since her study also lacked inclusion for nonverbal immediacy. Students explained that interpersonal touch, excessive movement, close distance and forms of gaze are inappropriate expressions for Japanese teachers. Thus, researchers who make assertions that Japanese have inclinations toward nonverbal behaviors such as U.S. delineated nonverbal immediacy based on Hall's (1966) classification of high context cultures should proceed with caution, since preferences for nonverbal immediacy may likely be superceded by preferences for culturally commensurable types of nonverbal behaviors.

While verbal immediacy preferences were markedly higher than nonverbal immediacy preferences, Japanese students ascribed different meanings to many of the verbal immediacy items they selected. This finding indicates that Japanese conceptualization of teacher immediacy may likely be different from the U.S. perspective. Interestingly, Japanese students described immediacy in their culture to function similar to instructional, relational, and personal dimensions that were described by Zhang \& Oetzel (2006) in their emic examination of immediacy from a Chinese perspective. Japanese students described an immediate teacher to be one who cared for their moral, personal, and instructional development. Again, this ties in with Confucian-based collectivism since the development of the whole person is of value in Japan. Nevertheless, it is noteworthy to point out that several verbal immediacy items were structured with priority in the map, which indicates that these behaviors, while they may mean something other than immediacy, are significant in the cultivation of teacher effectiveness in Japanese students' eyes.

Although Japan is identified to be high in power distance, Japanese students' influence map revealed students had preferences for teachers who reduce power distance with their students. Japanese students suggested that while it is atypical for teachers to violate the authority norms, they enjoy it when teachers do so with communication acts that convey closeness, care and connectedness within the instructional setting. Expectancy violation theory (Burgoon, 1978) could potentially be used to understand these effects since in several instances violations of norms have been found to ensue positive outcomes. Viewed collectively, the influence map indicated that Japanese students valued several teacher behaviors and characteristics that have been stereotypically associated with popular forms of expression utilized in the West. An explanation for this finding may be that in present day Japan, Japanese are expressing a stronger desire for Western style and/or individualistic forms of communication. In fact, Yum (1997) suggested "there have been substantial changes in the Asian societies since World War II. There has been an irrepressible influx of Western values; imported films and television programs are ubiquitous" (p. 87). In Japan, the co-existence of strong Confucian-based collectivism with new-age individualism should be expected if one accepts the premise that cultures are not static but dynamic. Triandis (1995) suggested that across cultures the self expresses both individualist and collectivist values to unique degrees. Thus, it is not surprising that amid rapid societal and progressive technological changes, Japanese students valued teacher communication that supported collectivistic expressions as well as individualistic expressions. Teacher behaviors and characteristics influenced a number of categories in the map; however, the plurality of elements structured in the map supported affective teacher characteristics foremost and clarity characteristics to a lesser extent. Japanese students explained that Japanese teachers support affective relationships with their students because they care about developing students into fine example Japanese citizens. Additionally, affective characteristics are important in rapport building. Building social rapport is woven into the fabric of Japanese culture and tradition as well, which is a collectivistic value. Students explained that just as rapport building is necessary in Japanese business transactions, rapport building is essential to the teacher-student relationship.

Additionally, the importance of the clarity category can be understood when one explores Japanese system rote memorization. The Asian assessment tasks reported in Baumgart and Halse's (1999) study "revealed the necessity for an extensive knowledge base but, in addition, demanded challenging skills in interpretation, translation, application and analysis" (p. 329). More precisely, the finding that clarification is necessary in the context of instruction in Japan may be suggestive of the possibility that learning from the approach of rote memorization in Asian societies requires a rich and deep understanding, so teacher behaviors and characteristics that support teacher clarity are valued.

In summary, the inclusion of elements in the map can be understood in light of the Confucian-based Japanese culture. The systems approach exploration of teacher effectiveness in Japan revealed that a host of teacher elements is responsible for student perceptions of teacher effectiveness.

\subsection{Implications, Limitations, and Future Research Directions}

It is not sufficient to assume that particular teacher behaviors or characteristics alone shape notions of teacher effectiveness. Consequently, the relative importance of teacher behaviors and characteristics in relation to each other is informative given the complex and dynamic nature of this phenomenon. In this study, the structural analyses produced through NGT and by ISM do not only provide systems for understanding teacher effectiveness, but also they establish a mechanism for understanding immediacy behaviors within systems. The study sets a foundation for understanding 'how' teacher effectiveness is supported through antecedent and succedent elements within an overall system that supports positive teacher outcomes. 
Comparisons between the cultural groups were beyond the scope of these preliminary emic qualitative studies; however, just as ethnographies can be compared across similar cultures when several ethnographies exist about a phenomenon, so can findings from consensus methodologies (e.g. influence maps) be compared when several of them have been performed (Broome \& Keever, 1989). Also, Carbaugh (1990) described how cross-cultural comparisons of communication phenomena should be approached through movements between what is known generally and what is known specifically as follows: etic-1 to emic to etic-2. Carbaugh (1990) suggested that "The first such phase presents a general etic framework of the phenomenon, which grounds the study conceptually, providing an initial orienting definition of the phenomenon..." and continued by suggesting that "In the second phase, the studies apply the etic framework heuristically in particular situations and communities, in order to discover the nature of such phenomena, and rules for its use, in local systems" (p. 291). In the last phase, Carbaugh described that "Finally... what the local systems (emic orders) suggest generally about the phenomena under study, a movement from emic back to the etic..." (p. 291). The current study is a contribution to the Carbaugh's (1990) second phase, which is the emic phase. In order to develop a global perspective of teacher effectiveness, future research should proceed through Carbaugh's (1990) three sequence approach.

This study presented only two cultural groups' qualitative notions of teacher effectiveness; however, cross-cultural instructional scholars can benefit from an increased qualitative understanding of teacher effectiveness from an emic perspective of other cultures. In light of diverse student populations present in classrooms, teachers who are open to adopting a variety of approaches may enhance their ability to be effective with disparate learners. Although this research did not examine individual teacher behaviors and/or characteristics in depth an important purpose was to provide an impetus for future research in this area. A recent study by Wanzer, Frymier, Wojtaszczyk and Smith (2006) provides an excellent example of the types of research that can spawn from the current research. Their study distinguished between appropriate and inappropriate types of humor within the U.S. instructional context. The study set forth rich descriptions of humor across category types. Along these lines, validating emic teacher immediacy scales within particular cultures is necessary so that teacher effectiveness can be assessed appropriately (Zang \& Oetzel, 2006). It was clear from the current study that immediacy behaviors in both verbal and nonverbal forms are not commensurable with the Japanese conceptualization of immediacy. Even more important, several immediacy behaviors are inappropriate for Japanese teachers to express. Interestingly, substantial support was found for verbal immediacy for both cultural groups, which should raise concerns over past research that has discouraged its assessment. A systems understanding of teacher communication is important, but an equally important area for scholars in future research is discovering emic meanings associated with particularly important teacher elements within cultures.

When teacher effectiveness research is advanced from a global perspective that encompasses an understanding of stylistic differences from a variety of instructional approaches in contrast to a single instructional approach, then teachers will be able to tap into new terrains of teacher effectiveness that may be cross-culturally useful. A global understanding of teacher effectiveness is important given that U.S. educators have been overly dismissive of the strategies and practices of teachers from different countries particularly since the practices are linked to different value orientations (Stefani, 1997). This is not to suggest a complete transformation of teacher approaches, but rather a creative blending of a variety of approaches that may likely benefit students from disparate cultures. Finally, the study has important implications for teachers since both groups expressed preferences for teachers who continuously learn about best teaching practices, theories, skills and behaviors. Teacher training and development seem to be linked to teacher effectiveness.

\section{Conclusion}

This study provides a new insight into the emic nature of teacher effectiveness with special consideration to the role of immediacy within two cultural groups from the U.S. and Japan. Future research should burgeon with the new conceptualization of teacher effectiveness set forth by this study to explore this phenomenon holistically.

Although analysis of all the items generated for this study was beyond the scope of the present article, analysis of the relatively more important elements should be the focus of future research. When this type of analysis is performed, an increased cultural understanding about notions of teacher effectiveness within several cultural groups is far more likely to develop.

\section{References}

Allen, M., Witt, P. L. \& Wheeless, L. R. (2006). The role of teacher immediacy as a motivational factor in student learning: Using meta-analysis to test a causal model. Communication Education. 55(1), 21-31.

Andersen, J. (1979). Teacher immediacy as a predictor of teaching effectiveness. In D. Nimmo (Ed.), Communication Yearbook (pp. 543-559). New Brunswick, N.J.: Transaction Books.

Andersen, P. A. (1998). The cognitive valence theory of intimate communication. In M.T. Palmer \& G. A. Barnett (Eds.), Progress in Communication Sciences, XIV (pp. 39-72). Westport, CT: Greenwood Publishing Group. 
Andersen, P. A. (2008). Nonverbal communication: Forms and functions $\left(2^{\text {nd }}\right.$ ed.). Prospect Heights, IL: Waveland Press.

Andersen, P. A., \& Wang, H. (2006). Unraveling cultural cues: Dimensions of nonverbal communication across cultures. In L. A. Samovar, R. E. Porter, \& E. R. McDaniel (Eds.), Intercultural Communication: A Reader (pp. 250-265). Belmont, CA: Thomson Wadsworth.

Asai, A., \& Barnlund, D. C. (1998). Boundaries of the unconscious, private, and public self in Japanese and Americans: A cross-cultural comparison. International Journal of Intercultural Relations, 22(4), 431-452.

Aubrecht, J.D. (1981). Reliability, validity and generalizability of student ratings of instruction. (IDEA Paper No. 2. Manhattan: Kansas State University, Center for Faculty Evaluation and Development. (ERIC document Reproduction Service No. ED213 296)

Baumgart, N., \& Halse, C. (1999). Approaches to learning across cultures: The role of assessment. Assessment in Education: Principles, Policy \& Practice, 6(3), 321-340.

Blumer, H. (1969). Symbolic interactionism: Perspectives and method. Englewood Cliffs, NJ: Prentice Hall.

Broome, B. J. (1991). Building shared meaning: Implications of a relational approach to empathy for teaching intercultural communication. Communication Education, 40(3), 235-249.

Broome, B. J. (1997). Designing a collective approach to peace: Interactive design and problem-solving workshops with Greek-Cypriot and Turkish-Cypriot communities in Cyprus. International Negotiation, 2(3), 381-407.

Broome, B. J. (1998). Overview of conflict resolution activities in Cyprus: Their contribution to the peace process. The Cyprus Review, 10(1), 47-66.

Broome, B. J., \& Christakis, A. N. (1988). A culturally-sensitive approach to Tribal governance issue management. International Journal of Intercultural Relations, 12, 107-123.

Broome, B. J., \& Cromer, I. L. (1991). Strategic planning for tribal economic development: a culturally appropriate model for consensus building. The International Journal of Conflict Management. 2(3), 217-233.

Broome, B. J., DeTurk, S., Kristjansdottir, E., S., Kanata, T., \& Ganesan, P. (2002). Giving voice to diversity: An interactive approach to conflict management and decision-making in culturally diverse work environments. Journal of Business and Management, 8(3), 239-263.

Broome, B. J., \& Keever, D. B. (1989). Next generation group facilitation: Proposed principles. Management Communication Quarterly, 3(1), 107-127.

Burgoon, J. K. (1978). A communication model of personal space violations: Explication and an initial test. Human Communication Research, 4(2), 129-142.

Burgoon, J. K. (1995). Cross-cultural and intercultural applications of expectancy violations theory. In R. L. Wiseman (Ed.). Intercultural Communication Theory (pp. 194-215). Thousand Oaks, CA: Sage.

Capella, J. N., \& Greene, J. O. (1982). A discrepancy-arousal explanation of mutual influence in expressive behavior for adult and infant-adult interaction. Communication Monographs, 49(1), 89-114.

Carbaugh, D. (1990). Cross-cultural comparisons of communication phenomena. In D. Carbaugh (Ed.). Cultural communication and intercultural contact (pp. 291-302). Hillsdale, NJ: Lawrence Erlbaum.

Cashin, W. E. (1994). Student ratings of teaching: A summary of the research. In K. A. Feldman and M. B. Paulsen (Eds.). Teaching and learning in the college classroom (pp. 531-541). Needham Heights, MA: Simon \& Schuster.

Chen, G., \& Chung, J. (1997). The "Five Asian Dragons": Management behaviors and organizational communication. In L. A. Samovar \& R. E. Porter (Eds.), Intercultural communication: A reader (8th ed.) (pp. 317-327). Belmont, CA: Wadsworth Publishing Company.

Collier, M. J., and Powell, R. G. (1986, May). The effect of student culture/ethnicity on judgments of instructional communication. Paper presented at the annual convention of the International Communications Association, Chicago, Illinois.

Collier, M. J., Ribeau, S. A., \& Hecht, M. L. (1986). Intercultural communication rules and outcomes within three domestic cultures. International Journal of Intercultural Relations, 10(4), 439-457.

Cupach, W. R., \& Imahori T. T. (1993). Managing social predicaments created by others: a comparison of Japanese and American facework. Western Journal of Communication, 57(4), 431-444.

Delbecq, A. L., Vande Ven, A. H., \& Gustafson, D. H. (1975). Group techniques for program planning. Glenview, IL: Scott, Foresman. 
Fuhrmann, P.S., \& Grasha, A. F. (1994). Toward a definition of effective teaching. In K. A. Feldman and M. B. Paulsen (Eds.). Teaching and learning in the college classroom (pp. 241-252). Needham Heights, MA: Simon \& Schuster.

Gay, G. (2006). Culture and communication in the classroom. In L. A. Samovar, R. E. Porter, \& E. R. McDaniel (Eds.), Intercultural Communication: A Reader (pp. 326-342). Belmont, CA: Thomson Wadsworth.

Gorham, J. (1988). The relationship between verbal teacher immediacy behaviors and student learning. Communication Education, 37(1), 40-53.

Hall, E. T. (1966). The hidden dimension. New York: Doubleday.

Hecht, M. (1993). 2002-A research odyssey: toward the development of a communication theory of identity. Communication Monographs, 60(1), 76-81.

Hofstede, G. (1980). Culture's Consequences. Beverly Hills, CA: Sage.

Johnson, S. D., \& Miller, A. N. (2002). A cross-cultural study of immediacy, credibility, and learning in the U.S. and Kenya. Communication Education, 51(3), 280-292.

Kearney, P., Plax, T. G., Smith, V. R., \& Sorensen, G. (1988). Effects of teacher immediacy and strategy type on college student resistance to on-task demands. Communication Education, 37(1), 54-67.

Kvale, S. (1996). InterViews: An introduction to qualitative research interviewing. Thousand Oaks, CA: Sage.

Martin, J. N., \& Nakayama T. K. (2000). Intercultural communication in context. Mountain View, CA: Mayfield.

McDaniel, E. R. (2006). Japanese nonverbal communication: A reflection of cultural themes. In L. A. Samovar, R. E. Porter, \& E. R. McDaniel (Eds.), Intercultural Communication: A Reader (pp. 266-274). Belmont, CA: Thomson Wadsworth.

Mehrabian, A. (1971). Silent messages. Belmont, CA: Wadsworth Publishing Company.

Morse, J. M. (1994). Designing Funded Qualitative Research. In N. K. Denzin \& Y. S. Lincoln (Eds.), Handbook of qualitative research (pp. 220-235). Thousand Oaks, CA: Sage.

Mottet, T. P., \& Richmond, V. P. (1998). An inductive analysis of verbal immediacy: Alternative conceptualization of relational verbal approach/avoidance strategies. Communication Quarterly. 46(1), 25-40.

Mulder, M. (1977). The Daily Power Ggame. Leyden, The Netherlands: Martinus Nijhoff.

Myers, S. A., Zhong, M., \& Guan, S. (1998). Instructor immediacy in the Chinese college classroom. Communication Studies, 48(3), 240-254.

Neuliep, J. W. (1997). A cross-cultural comparison of teacher immediacy in American and Japanese college classrooms. Communication Research, 24(4), 431-451.

Nishida, T. (1996). Communication in personal relationships in Japan. In W. B. Gudykunst, S. Ting-Toomey, \& T. Nishida (Eds). Communication in personal relationships across cultures (pp. 102-121). Thousand Oaks, CA: Sage.

Nussbaum, J. F., Javidi, M., Downs, V.C., \& Holladay, S. J. (1986). Verbal communication within the college classroom. Paper presented at the Annual Convention of the International Communication Association, Chicago, IL.

Powell, R. G., \& Arthur R. (1985). Perceptions of affective communication and teaching effectiveness at different times in the semester. Communication Quarterly, 33(4), 254-261.

Powell, R., \& Harville B. (1990). The effects of teacher immediacy and clarity on instructional outcomes: An intercultural assessment. Communication Education, 39(4), 369-379.

Richmond, V., Gorham, J., \& McCroskey, J. (1987). The relationship between selected immediacy behaviors and cognitive learning. In M. McLaughlin (Ed.), Communication Yearbook (pp. 574-590). Beverly Hills, CA: Sage.

Roach, K. D. \& Byrne, P.R. (2001). A cross-cultural comparison of instructor communication in American and German classrooms. Communication Education, 50(1), 1-14.

Robinson, R. Y., \& Richmond, V. P. (1995). Validity of the verbal immediacy scale. Communication Research Reports. 12(1), 80-84.

Sanders, J. A., \& Wiseman, R. L. (1990). The effects of verbal and nonverbal teacher immediacy on perceived cognitive, and behavioral learning in the multicultural classroom. Communication Education, 39(4), 341-353.

Schellenberg, J. A. (1996). Conflict resolution: Theory, research, and practice. Albany, NY: State University of New York Press.

Schwarz, R. (2002). The skilled facilitator: A comprehensive resource for consultants, facilitators, managers, trainers, and coaches. San Francisco: Jossey-Bass. 
Shuter, R. M. (1998). Revisiting the centrality of culture. In J. N. Martin, T. K. Nakayama \& L. A. Flores (Eds.), Readings in Cultural Contexts. Mountain View, CA: Mayfield.

Smythe, M. J., \& Hess, J. A. (2005). Are student self-reports a valid method for measuring teacher nonverbal immediacy? Communication Education, 54(2), 170-179.

Stefani, L. A. (1997). The influence of culture on classroom communication. In L. A. Samovar \& R. E. Porter (Eds.), Intercultural communication: A reader (8th ed.). (pp. 349-362). Belmont, CA: Wadsworth Publishing Company.

Tanno, D. V. \& Jandt, F. E. (1994). Redefining the "other" in multicultural research. The Howard Journal of Communications, 5 (1/2), 36-45.

Teven, J. J., \& Hanson, T. L. (2004). The impact of teacher immediacy and perceived caring on teacher competence and trustworthiness. Communication Quarterly, 52, 39-53.

Thomas, C. E., Richmond, V. P. \& McCroskey, J. C. (1994). The association between immediacy and socio-communicative style. Communication Research Reports, 11, 107-115.

Triandis, H. C. (1995). Individualism and Collectivism. Boulder, CO: Westview.

Wanzer, M. B. \& Frymier, A. B. (1999). The relationship between student perceptions of instructor humor and students' reports of learning. Communication Education, 48(1), 48-62.

Wanzer, M.B., Frymier, A.B., Wojtaszczyk, A.,Smith, T. (2006). Appropriate and inappropriate uses of humor by teachers. Communication Education, 55(2), 178-196.

Warfield, J. N. (1976). Societal systems: Planning, policy and complexity. New York: Wiley.

Warfield, J. N. (1982). "Interpretive Structural Modeling”. In S.A. Olsen (Ed.), Group Planning and Problem-solving Methods in Engineering (pp. 155-201). New York: Wiley.

Warfield, J. N. (1995). A science of generic design: Managing complexity through systems design. Ames: Iowa State University Press.

Warfield, J. N., \& Cardenas, A. R. (1995) A Handbook of Interactive Management. Ames: Iowa State University Press.

Yum, J. O. (1997). The impact of Confucianism on interpersonal relationships and communication patterns in East Asia. In L. A. Samovar \& R. E. Porter (Eds.), Intercultural Communication: A reader (7th ed.). (pp. 78-88). Belmont, CA: Wadsworth Publishing Company.

Zhang, Q., \& Oetzel, J. G. (2006). Constructing and validating a teacher immediacy scale: A Chinese perspective. Communication Education. 55(2), 218-241.

Zhang, Q., Oetzel, J. G., Gao, X., Wilcox, R. G., \& Takai, J. (2007). Teacher immediacy scales: Testing for validity across cultures. Communication Education. 56(2), 228-248. 


\section{Appendix A.}

Summary of U.S. Student's Categories and Priority Items for Each Category

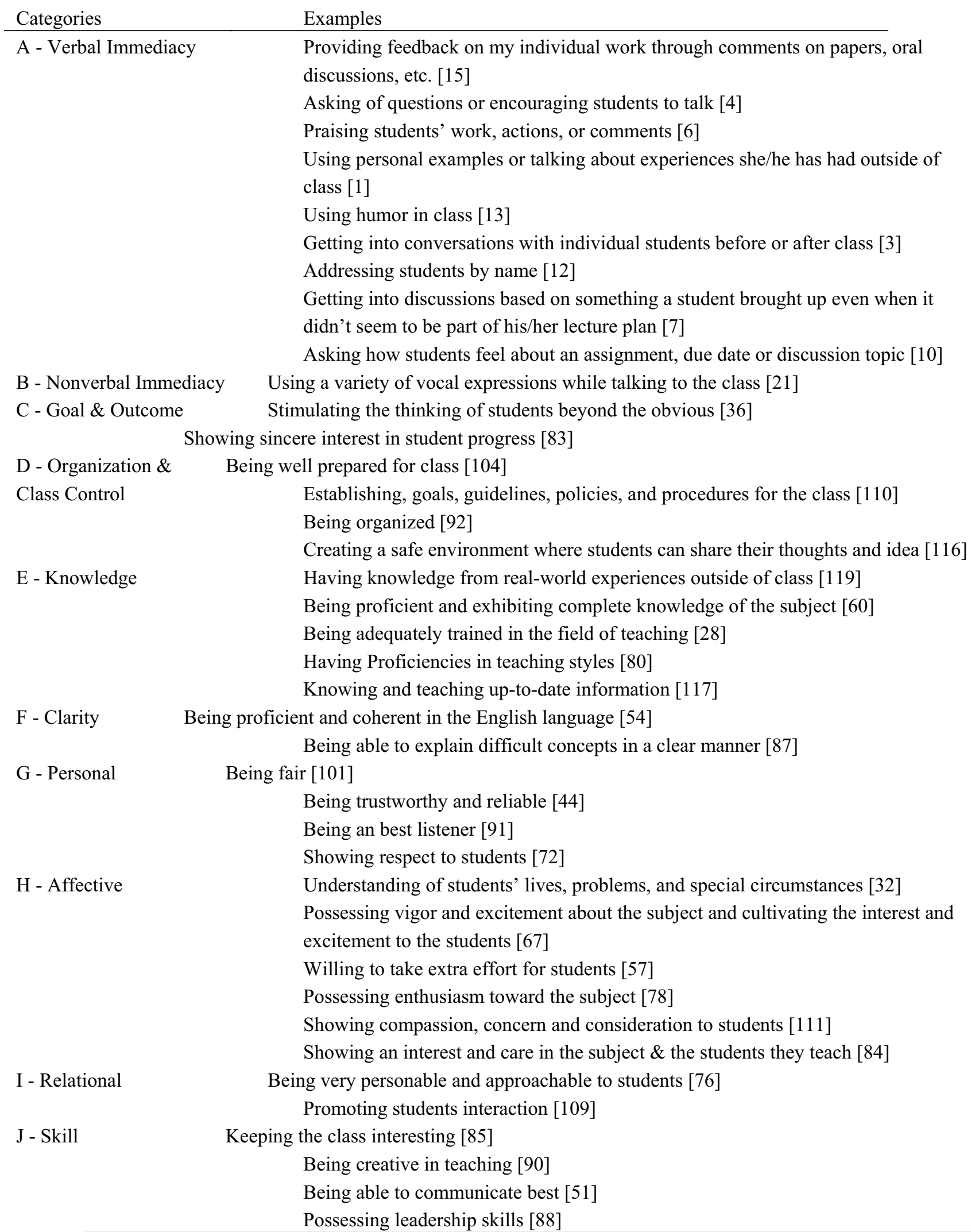




\section{Appendix B.}

Summary of Japanese Student's Categories and Priority Items for Each Category

Categories

A - Verbal Immediacy

\section{Examples}

Providing feedback on my individual work through comments on papers, oral discussions, etc. (15)

Getting into conversations with individual students before or after class (3)

Inviting students to telephone or meet with him/her outside of class if they had questions or wanted to discuss something (14)

Using humor in class (13)

Using personal example or talking about experiences she/he has had outside of class (1)

Asking of questions or encouraging students to talk (4)

Asking questions that solicited viewpoints or opinions (11)

B - Nonverbal Immediacy Looking at the class a lot while teaching (19)

Using a variety of vocal expression while talking to the class (21)

C - Goal \& Outcome

Getting students to think by themselves (103)

Motivating students to learn (121)

Establishing students' interest in studying (109)

D - Organization \& Creating a good structure and organization to class (117)

Class Control

E - Knowledge

Having knowledge in many different areas (25)

Having real-world experience outside of the class (111)

Having proficiencies in teaching and teaching styles (35)

Having adequate teaching ability and/or communicative skills (26)

Having a good understanding of the material being taught (44)

F - Clarity

Teach step by step so that it is easy for students to follow (93)

Checking if students can understand material or not (119)

Establishing clear messages (61)

G - Personal Being fair (31)

Being unique (27)

$\mathrm{H}$ - Affective $\quad$ Being encouraging and supportive of students (83)

Willing to help students (33)

Showing an enjoyment toward teaching (67)

Possessing a positive attitude and behavior (85)

Showing interest in students' opinions (82)

Understanding students' personal problems and concerns (88)

J - Skill

Providing course material with examples to everyday life (81)

Having a lecture skill that catches students' attention in class (95) 


\section{Appendix C.}

U.S. Students' Supportive Cultivation Map

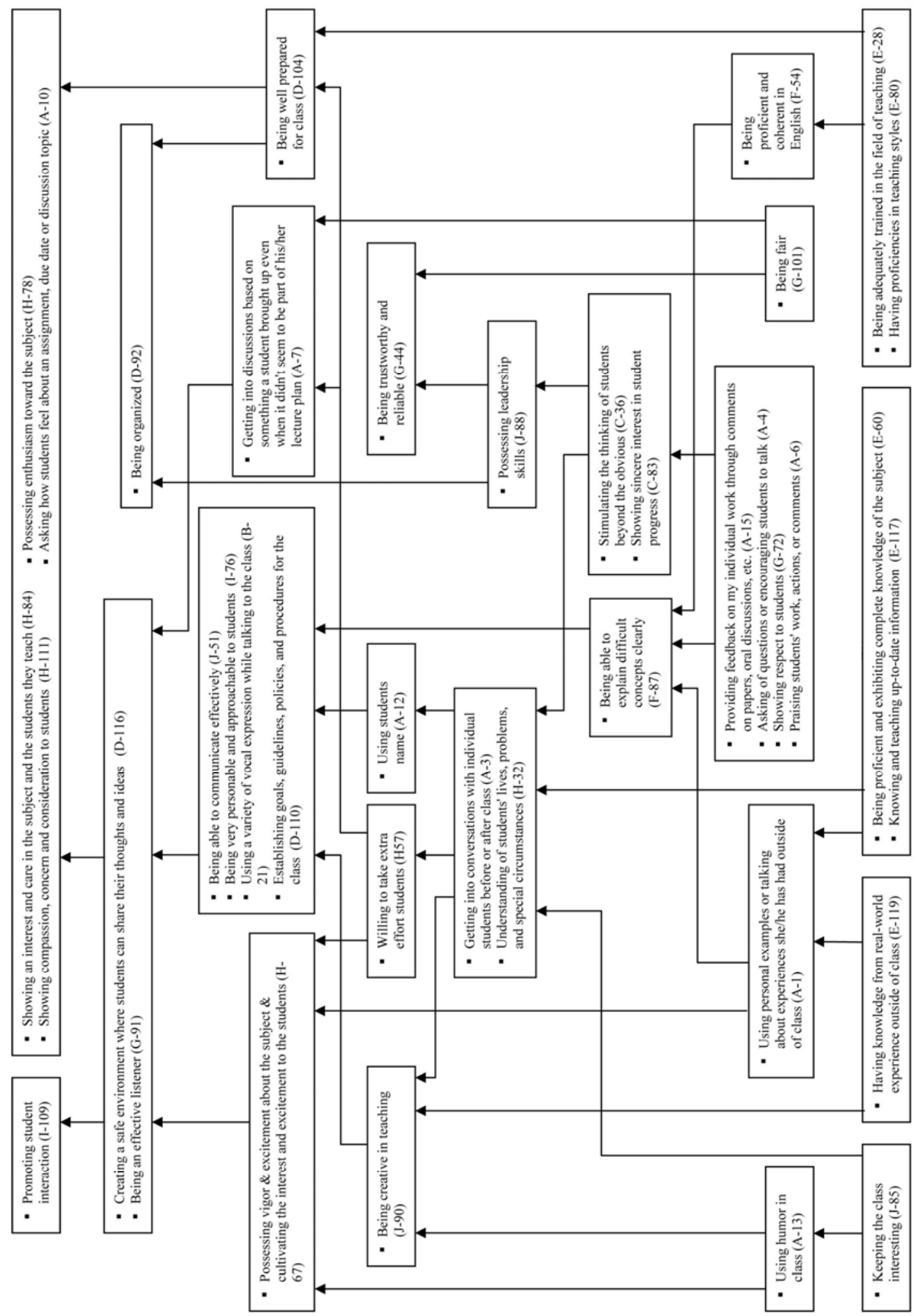




\section{Appendix D.}

Japanese Students' Supportive Cultivation Map

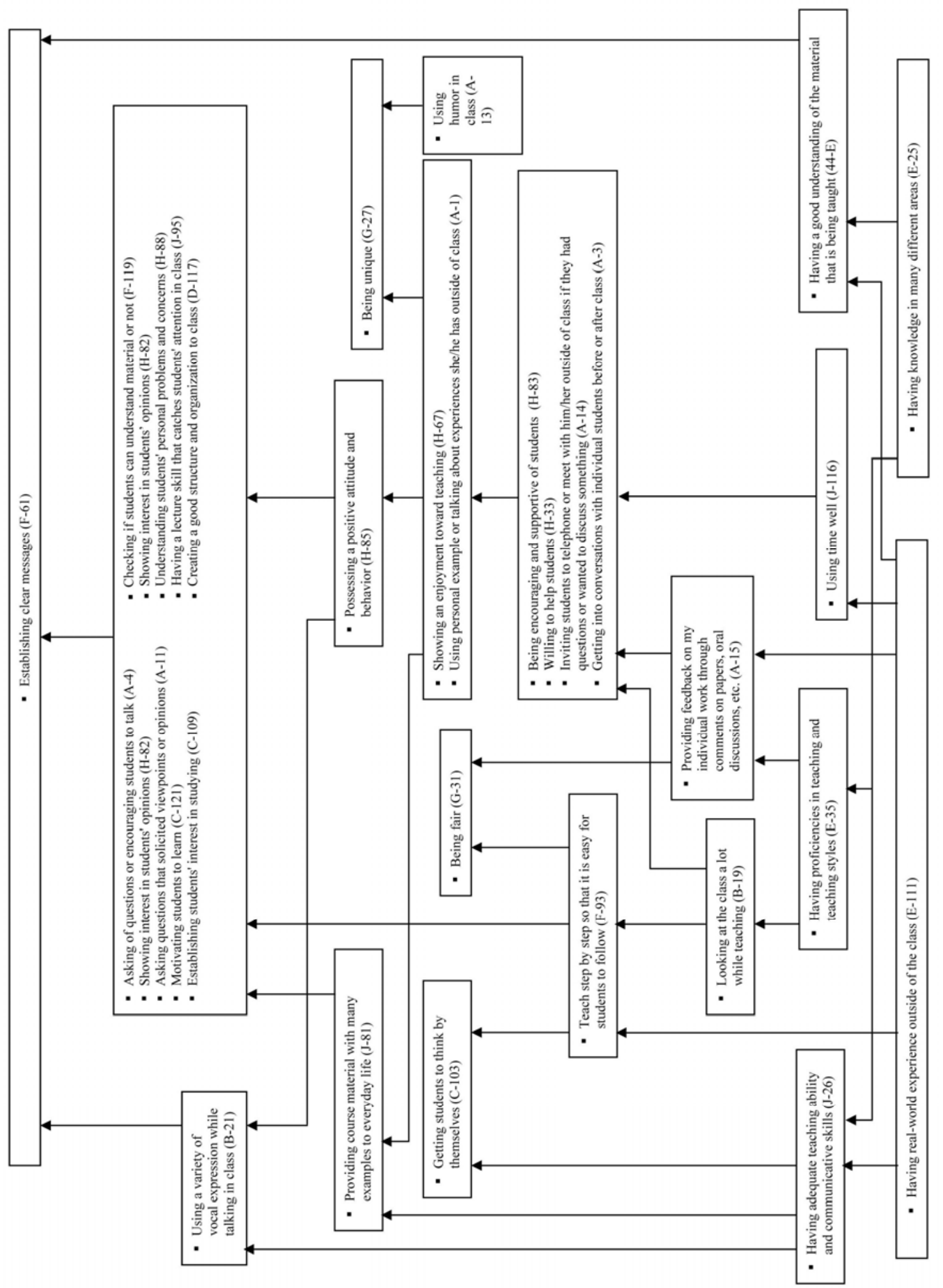

